\title{
The Current Situation and Prospect of Cell Phone APP in Auto Rescue
}

\author{
Jiang $\mathbf{Y i}$ \\ ${ }^{1}$ International College Beijing, China Agricultural \\ University, Beijing, 100083, P.R.China \\ Tian Xunan ${ }^{1}$ \\ ${ }^{1}$ International College Beijing, China Agricultural \\ University, Beijing, 100083, P.R.China
}

\author{
Li $\operatorname{Ran}^{1}$ \\ ${ }^{1}$ International College Beijing, China Agricultural \\ University, Beijing, 100083, P.R.China

\section{Luan Zhiqiang ${ }^{2}$} \\ ${ }^{2}$ Corresponding author, International College Beijing, \\ China Agricultural University, Beijing, 100083, P.R.China
}

\begin{abstract}
This research is carried out based on the consumer behavior field, aims to analyze and give explanations of both the current situation and the prospect of cell phone APP in auto rescue. This paper introduces the disadvantages of the existing rescue APP. Questionnaires, in-depth interviews and observation were used as research methods in order to expand market and prove the public necessity on APP. Primary data is collected and analyzed by SPSS. Then, the functions of rescue APP that people need and the gap between conceiving and implementing are derived. Finally, recommendations are listed.
\end{abstract}

Keywords: cell phone APP, auto rescue, consumer behavior

\section{Introduction}

In the $21^{\text {st }}$ century, the automobile industry is developing rapidly in China. The profit from selling the actual automobile is decreasing, and the main profit point is inclined to after-sale service, which creates $50 \%$ to $60 \%$ at the profit in the whole industrial chain all over the world ${ }^{[1]}$. However, as a part of after-sale service, the development of auto rescue is far behind the $15 \%$ to $20 \%$ growth in Chinese automobile holdings. That means auto rescue becomes a bigger and bigger wind fall and its market prospect will be over one hundred billion ${ }^{[2]}$. The basic rescue service should include: delivering of petrol, battery charging, tire replacement, quick repairing on road, towing cars, and designated driver service. Nowadays, the automobile rescue market is mainly occupied by automobile club, car sales agencies such as $4 \mathrm{~S}$ stores, auto repair businesses, specialized towing companies and insurance companies ${ }^{[3]}$. In November 2008, IBM proposed a new concept called Smarter Planet. This idea made the beginning of new innovation. With the rapid development of smart phones in the world, the sales volume reached 9.68 billion worldwide in $2013^{[4]}$. So, in this information-based age, when lots of people have smart phones, linking the APP with auto rescue is just around the corner.

An automobile rescue APP is available to people when some car accidents occur. The APPs are supposed to have GPS. When cars break down on the road, the APP can provide the information of the nearest maintenance shops and people can easily solve the problems using their phone by connecting with the $4 \mathrm{~S}$ shops or other private shops.

These APPs are convenient for drivers in China, especially in a big city or in an unfamiliar city. However, the automobile rescue APP is still not widespread, and the functions of the only existing rescue APP in China are not mature, so few people use it.

The one existing rescue APP is "KUAI XIU XIAN SHENG", and its disadvantages are obvious. First, most of the maintenance stores it cooperates with are small stores, and no formal $4 \mathrm{~S}$ stores are provided. Currently, the APP provides little profit for $4 \mathrm{~S}$, so the company has not shown much interest. Second, the design and functions of the APP are too simple, it doesn't provide useful information, and there is no category of common problems. So when drivers meet problems on road, they cannot find the helpful services. Third, after calling the stores, it is found that many of stores cannot provide the rescue services as the APP promises. Fourth, this APP focuses more on providing services like washing the car rather than rescue.

To sum up, the existing rescue APP's functionality is limited to providing "quick rescue" service. The following analysis will be used to prove that people really need a rescue APP. Based on existing rescue APP, methods of improvement will be raised according to the analysis of analyzing people`s needs.

\section{Research Methods}

\subsection{Questionnaire}

This section of the study is based on online research in order to improve the functions of the cell phone APP for 
auto rescue and to investigate whether people are willing to use it. The questionnaire focuses on people who possess cars or who frequently drive them. 440 effective questionnaires were collected.

In order to find out the common problems the drivers may come across when driving and their ideas about the auto rescue APP the questionnaire is consists of six multiple choice questions and a short answer question.

The questions pertain to what kind of incidents drivers will encounter during driving, and how they will commonly solve those problems, whether drivers will consider using auto rescue APP when their cars have trouble, and the reasons drivers refuse to use such an APP. In addition, subjects are requested to provide some useful and practical suggestions to improve the APP at the end of the questionnaire. The recommendations will be provided based on the result of the research.

\subsection{In-depth Interview}

The interviewee is the manager of a Ford maintenance department at $4 \mathrm{~S}$ stores. The interview was conducted by telephone. The aim was to know the interviewee's opinion of the rescue APP and the cooperation between $4 \mathrm{~S}$ stores and APPs from the point of view of $4 \mathrm{~S}$ stores. The in-depth interview was conducted non-randomly.

\subsection{Observation}

In order to know more about the existing rescue APP and find out the problems it has, researchers went to the private maintenance shops which cooperate with the APP.

\subsection{Secondary Research}

Only one existing rescue APP was found and was used as the secondary resource. Research was carried out based on this existing technology.

\section{Data analysis and Discussion}

After collection, the coded data was entered into SPSS. Recomm

$\begin{array}{llllll}\text { endation } & \mathbf{1} & \mathbf{2} & \mathbf{3} & \mathbf{4} & \mathbf{5}\end{array}$

s are summarized from the analysis.

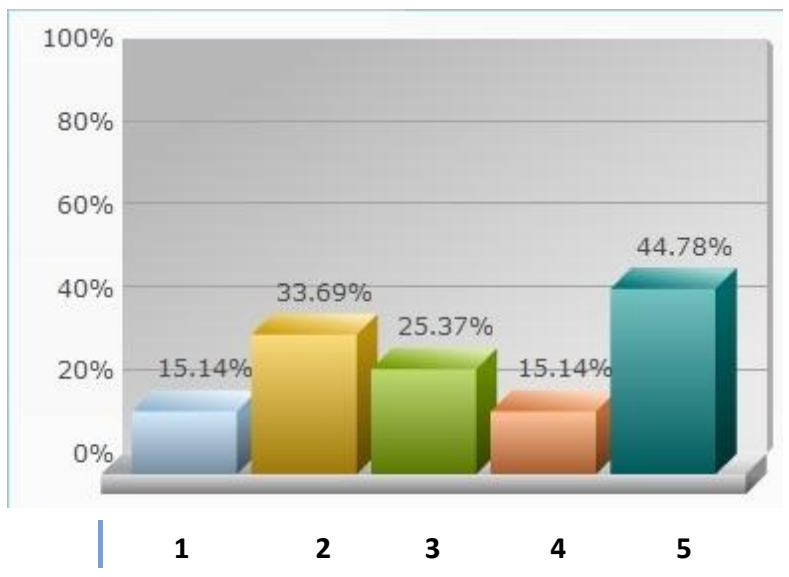

Fig.1 The problem people meet

1.No petrol and you have to stop

2.The car cannot start because of a dead battery

3.Tire burst and need to change the tire

4. Tow because of a malfunction

5.I have never encountered those things

The column chart Fig.1 shows the problems people came across. From the figure, it can be seen that more than half of the sample have came across problems during driving. So rescue is a significant problem that most of drivers must face and cannot avoid. Therefore, the potential rescue market is large, and an appropriate rescue APP may have a good prospect if put into market. Fig. 2 presents people preferences when they have problems. It shows that most people would like to choose the formal $4 \mathrm{~S}$ stores and the store nearby. There are also a group of people who would like to try the rescue APP. So after improving and combining APP with other major preferences, more people will accept the APP.

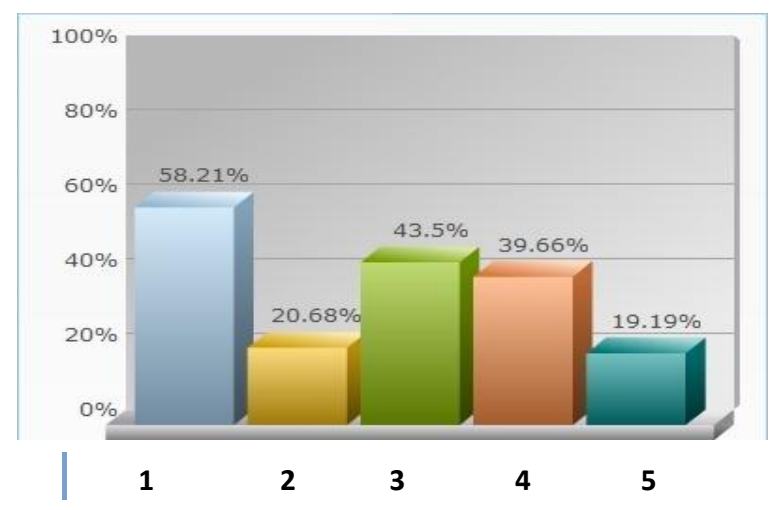

Fig. 2 The way people choose to solve the problem

1.Call the $4 \mathrm{~S}$ shop

2.Use the APP on the mobile phone to search

3. Choose a store nearby

4.Consult friends or relatives

5.Solve the problem by yourself 
Analysis revealed that, $85.07 \%$ of people never touched this kind of APP before. Therefore, it is an emerging market so the development space for the rescue APP is huge. Moreover, statistical data shows $92.23 \%$ of people would like to try the APP if available; it can be judged that the prospect for this APP is positive. People are willing to try its functionality. So according to the analysis above, it can be known that this APP is necessary and needs to be better developed.

According to the in-depth interview, the manager of the Ford maintenance department pointed out that the main problems people come across are tire bursts and dead batteries. Usually when these happen, if the drivers wants help from $4 \mathrm{~S}$ stores, they need to wait at least 30 minutes. So it is not timely for people. And when it comes to more serious problems, drivers need to call $4 \mathrm{~S}$ stores to make an appointment before getting help. It means that $4 \mathrm{~S}$ stores may not provide help to drivers in time. If the rescue APP can be used, drivers will find the nearest maintenance shop and have more relevant information about the shop's services and more conveniently solve those two common problems. Furthermore, the manager said that the reason why $4 \mathrm{~S}$ shops were not enthusiastic about this cooperation was that there was little profit for $4 \mathrm{~S}$ shops. So the APP developers need to find out a way to attract $4 \mathrm{~S}$ shops. Only in this way, can the APP be more multifunctional and trust worthy.

Similarly, this study aimed to discover what functions people need in APP. Relations are found between the problems people came across and the ways of solving problems using the Multiple Linear Regression Model. Tab.1 gives the relationship between the solution "choose the shop nearby" and the types of problems people met. From the table, there is no relationship between gender and this solution. But the significants of other models are less than 0.001 , so the relationships exist. And the B for Model 4 and Model 5 are the biggest, it indicates the stronger relationships between them, which means that people are more likely to choose the shop nearby when required to change new tire and trailer because of malfunctions. It shows that people hope to solve emergencies quickly by principle of proximity. So the rescue APP must provide the shop nearby for people.
Tab.1 relationship between the solution "choose the shops nearby" and all kinds of problem people met.

\begin{tabular}{|c|c|c|c|c|c|c|}
\hline \multicolumn{7}{|c|}{ Coeffecient $^{\Xi}$} \\
\hline \multirow{2}{*}{\multicolumn{2}{|c|}{ modle }} & \multicolumn{2}{|c|}{ Unstandardized Coeffecient } & \multirow[t]{2}{*}{$\begin{array}{l}\text { Standardized } \\
\text { Coeffecient }\end{array}$} & \multirow[b]{2}{*}{$t$} & \multirow[b]{2}{*}{ Sig. } \\
\hline & & $B$ & Std.Error & & & \\
\hline \multirow[t]{7}{*}{1} & (constant) & .185 & .106 & & 1.743 & .082 \\
\hline & 1. & .034 & .047 & .033 & .710 & .478 \\
\hline & 2. & .510 & .068 & .507 & 1.483 & .000 \\
\hline & 3. & .513 & .064 & .512 & 1.975 & .000 \\
\hline & 4. & .719 & .062 & .717 & 3.064 & .000 \\
\hline & 5. & .827 & .069 & .817 & 3.294 & .000 \\
\hline & 6. & .411 & .075 & .411 & 1.407 & .000 \\
\hline
\end{tabular}

1.Gender

2.No petrol and you have to stop

3.The car cannot start because of a dead battery

4. Tire burst and need to change new tire

5.Tow because of malfunction

6.I have never encountered those things

(For Tab.1, Tab.2 and Tab.3)

Tab. 2 presents the relationship between the solution "call the formal $4 \mathrm{~S}$ stores" and the types of problems people faced. The B for model 4 is the biggest, so when people need to change tires, they prefer to call $4 \mathrm{~S}$ shops to change the tire with the high quality and well-known brand.

Tab.3 shows the relationship between the solution method "using APP" and the problems people met. The B for model 2 and model 3 is the biggest. So it can be easily seen that when people encounter problems like no petrol or the car cannot start because of a dead battery, they want to use an APP.

Tab. 2 relations between solving method "call the formal 4S stores" and all kinds of problems people faced

\begin{tabular}{|c|c|c|c|c|c|c|}
\hline \multirow{2}{*}{\multicolumn{2}{|c|}{ modle }} & \multicolumn{2}{|c|}{ Unstandardized Coeffecient } & \multirow[t]{2}{*}{$\begin{array}{l}\text { Standardized } \\
\text { Coeffecient }\end{array}$} & \multirow[b]{2}{*}{$t$} & \multirow[b]{2}{*}{ Sig. } \\
\hline & & B & Std. Error & & & \\
\hline \multirow[t]{7}{*}{1} & (constant) & .303 & .107 & & 2.849 & .000 \\
\hline & 1. & .068 & .048 & .067 & 1.432 & .000 \\
\hline & 2. & .203 & .069 & .202 & .413 & .000 \\
\hline & 3. & .413 & .065 & .412 & 2.001 & .000 \\
\hline & 4. & .810 & .062 & .103 & .850 & .000 \\
\hline & 5. & .730 & .069 & .722 & 4.291 & .000 \\
\hline & 6. & .619 & .076 & .619 & 2.461 & .000 \\
\hline
\end{tabular}


Tab.3 relationship between the solving method "using APP" and problems people met

\begin{tabular}{|c|c|c|c|c|c|c|}
\hline \multicolumn{7}{|c|}{ Coefficients $^{\Xi}$} \\
\hline \multirow{2}{*}{\multicolumn{2}{|c|}{ modle }} & \multicolumn{2}{|c|}{ Unstandardized Coefficients } & \multirow[t]{2}{*}{$\begin{array}{c}\text { Standardized } \\
\text { Coefficient }\end{array}$} & \multirow[b]{2}{*}{$t$} & \multirow[b]{2}{*}{ Sig. } \\
\hline & & $B$ & Std.Error & & & \\
\hline 1 & constant & .074 & .009 & & .845 & .399 \\
\hline & 1. & -.024 & .004 & -.030 & -.623 & .240 \\
\hline & 2. & .740 & .056 & 680 & 2.903 & .000 \\
\hline & 3. & .650 & .053 & .640 & 2.215 & .000 \\
\hline & 4 & .340 & .051 & .340 & 1.374 & .000 \\
\hline & 5. & .420 & .057 & .380 & 1.832 & .000 \\
\hline & 6. & .680 & .062 & .660 & 2.417 & .000 \\
\hline
\end{tabular}

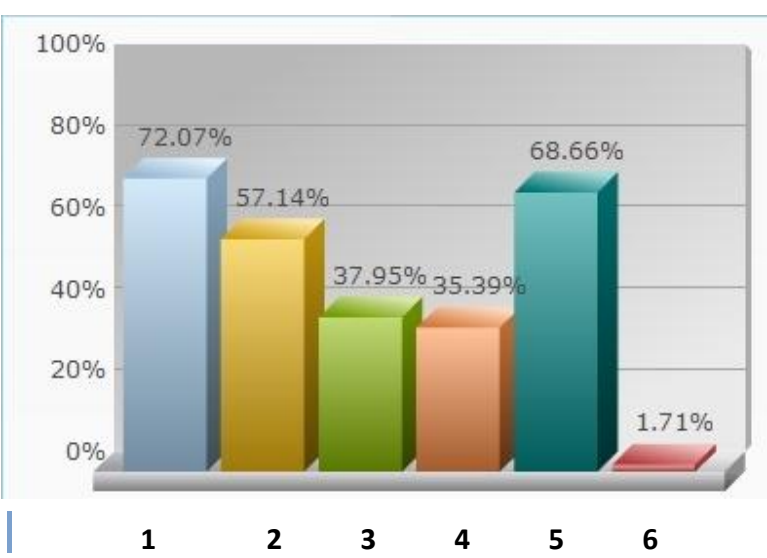

Fig. 3 the functions people hope for the APP

1.The APP can auto register and provide specific information about the store nearby.

2.Common problem can be solved by directly submitting the order to the store in the APP

3.A platform for car owners to communicate

4.Group purchase and coupon information

5.Call the APP rescue service and solve the problem via cell phone instruction

6.Other

So from the three tables, it is clear that the rescue APP can be widely used if it can help people connect with the maintenance stores nearby and the $4 \mathrm{~S}$ stores, and solve common problems as well.

Fig.3 shows the functions which people hope the APP can have. As a result, the APP which is able to tell people which maintenance stores can solve those problems they are facing is the most sought after. Meanwhile, the requirements for other functions are also proposed.

\section{Conclusions}

According to the results of survey, both customers and auto rescue merchants have different demands of such rescue APPs. However, the imperfect existing APP and low profit margins limit the rescue APP market development. In order to improve the current situation, recommendations are listed.

\subsection{Increase the Amount of Information in the APP that is Available for Customers}

First, the APP should show a greater number of surrounding shops which can provide rescue, as well as the shops' information. For example: prices, main business scope, shop appearance and specific location.

\subsection{Add Drivers Communication Platform}

In order to help drivers make informed decisions the APP should provide a platform for drivers to share experiences, opinions about driving or service providers, and make comments.

\subsection{Add Frequent Problems Classification and Solutions}

If frequent driving problems and solutions are part of into the APP, drivers can better handle the small problems quickly and conveniently. For instance, for the problems such as vehicle overheating, drivers can call the APP hotline directly and get instruction. Moreover, if the frequent problems are classified, drivers can choose problems they are facing and submit order forms in time and wait for rescue.

\subsection{Branding and Publicity}

It is important to create positive word of mouth to create public interest. To achieve this goal, rescue providers must deliver reliable and valuable information to consumers for them to positively transmit good information. Furthermore, branding is also key for the success of the APP. Successful branding helps profitability and provides a firm base for future expansion by building long-term relationship with $4 \mathrm{~S}$ stores or other automobile service institutions ${ }^{[5]}$.

\subsection{Strengthen and Cooperate with Automobile Service stations and $4 \mathrm{~S}$ Shops}

Strengthen cooperate, and negotiate to provide preferential group buying or discounts that can increase the number of customers and amount of usage. Thus, it can stimulate consumption in car washing, car care and car maintenance or other daily services. Meanwhile, it can bring more customers and profits to those service institutions. 


\section{References}

[1] L.Z. Wang. "The evaluation and research on the competitiveness of the after sale service of the car", Chang An University, Shan Xi, pp.2

[2] H.P. Qiu. "Auto rescue: a new tempting cake of after sale market”, China Auto Market, Beijing, 2007, p.39.

[3] Y. Liu. "Prospect of auto rescue service", China
Business Update, Yuhui, Liu, Beijing, 2014, p.78.

[4] M. Chen "Discussion of how to deal with the "337 investigation" storm invasion of Chinese smart phone enterprise", Video Engineering, State Intellectual Property Office Beijing, 2014, p280

[5] Y. Cao "Automobile Aftermarket Management - Major problems and recommendations of car rental industry in China's mainland". China Agricultural University Press, Beijing, 2010, p.115-117. 